\title{
The Improvement of Platinum Recovery Ratio in the Recycling Process Using "Dry Aqua Regia"*
}

\author{
Akihiro Yoshimura and Yasunari Matsuno \\ Graduate School of Engineering, Chiba University, Chiba 263-8522, Japan
}

\begin{abstract}
The authors have investigated a novel process of platinum recycling using "dry aqua regia". In our previous work, the recovery of platinum was successfully conducted by solvent leaching, but it yielded a mixture of $\mathrm{K}_{2}\left(\mathrm{PtCl}_{6}\right)$ and $\mathrm{FeO}_{\mathrm{x}}$. In this study, a solid-liquid separation process using $\mathrm{KCl}$ and $\mathrm{NaCl}$ solutions and a precipitation process using $\mathrm{NH}_{4} \mathrm{Cl}$ were adopted to obtain pure platinum. Impurities like $\mathrm{FeCl}_{3}$, $\mathrm{FeO}_{\mathrm{x}}$, and $\mathrm{KCl}$ were removed by a solid-liquid separation process, and pure $\left(\mathrm{NH}_{4}\right)_{2}\left(\mathrm{PtCl}_{6}\right)$ was obtained by $\mathrm{NH}_{4} \mathrm{Cl}$ addition. Then, the obtained $\left(\mathrm{NH}_{4}\right)_{2}\left(\mathrm{PtCl}_{6}\right)$ was calcinated to yield pure platinum by thermal decomposition. High-purity platinum was obtained with a recovery ratio of up to $79 \%$. Therefore, the usability of the recycling process using "dry aqua regia" was significantly improved. [doi:10.2320/matertrans.MT-M2019167]
\end{abstract}

(Received June 17, 2019; Accepted July 18, 2019; Published August 30, 2019)

Keywords: dry aqua regia, molten salt, platinum, recovery, solid-liquid separation

\section{Introduction}

Platinum $(\mathrm{Pt})$ and palladium $(\mathrm{Pd})$ are platinum-group metals (PGMs), which are important metals for jewelry, coins, and other industrial applications, particularly owing to their high catalytic abilities and chemical stability. They are often used as automotive catalysts consisting of approximately $40 \%$ platinum and approximately $75 \%$ palladium and rhodium. ${ }^{1,2)}$

While the ore grade of PGMs is very low, their grade in automotive catalysts is required to be relatively high, and therefore, recycling efforts have been actively pursued. However, both the commonly used pyrometallurgical process and hydrometallurgical process impose large environmental loads owing to the energy consumption arising from the generation of waste liquids, use of chlorine $\left(\mathrm{Cl}_{2}\right)$, and other factors. ${ }^{3)}$ Therefore, various new methods have been proposed, including a recently proposed process that utilizes a molten salt. ${ }^{4,5)}$ However, it lacks user-friendliness because it requires additional treatment like electrolysis or chlorine gas blowing. Despite the existing patented technology for recovering platinum by depositing the ore in a molten salt and directly chlorinating the containing platinum, ${ }^{6)}$ the treatment is difficult owing to the use of ammonium nitrate $\left(\mathrm{NH}_{4} \mathrm{NO}_{3}\right)$ and ammonium chloride $\left(\mathrm{NH}_{4} \mathrm{Cl}\right)$, which are raw materials of gunpowder.

Based on the above, the authors have proposed a new recycling method that uses an iron chloride (III) $\left(\mathrm{FeCl}_{3}\right)$ potassium chloride (KCl)-based molten salt. ${ }^{5)}$ By this method, platinum will be chlorinated into potassium hexachloroplatinate (IV) $\left(\mathrm{K}_{2}\left[\mathrm{PtCl}_{6}\right]\right)$ by the reaction shown in eq. (1). During the reaction, the chlorine in iron chloride (III) chlorinates platinum directly, removing the need for chlorine gas blowing. Additionally, the melting point of iron chloride (III) will be depressed drastically by the addition of potassium chloride, so that platinum can be chlorinated between $600-650 \mathrm{~K}$. Because the general processes that using molten salts require treatment at approximately $800-1600 \mathrm{~K}$,

*This Paper was Originally Published in Japanese in J. Japan Inst. Met Mater. 83 (2019) 250-255. this method suggests a dissolution technique with smaller environmental loads compared to those of traditional methods.

$$
\mathrm{Pt}+4 \mathrm{FeCl}_{3}+2 \mathrm{KCl} \rightarrow \mathrm{K}_{2}\left[\mathrm{PtCl}_{6}\right]+4 \mathrm{FeCl}_{2}
$$

For the post-treatment recovery, each composition containing potassium hexachloroplatinate (IV), produced as shown in eq. (1), used an expressed solubility different to that of the solvent, such as water and ethanol. Specifically, the lowsolubility potassium hexachloroplatinate (IV) was recovered by leaching coagulated molten salt with water or ethanol and removing the high-solubility iron chloride (III) and potassium chloride.

As shown in Fig. 1, the method of recycling using the iron chloride (III)-potassium chloride molten salt is capable of being achieved by the above steps. Because the molten salt possesses advantages such as being a solid at room temperature and the ability to dissolve highly oxidationresistant platinum without blowing chlorine gas or using electrolysis, the authors have named it as "dry aqua regia" citing a concept in an existing patent. ${ }^{6}$

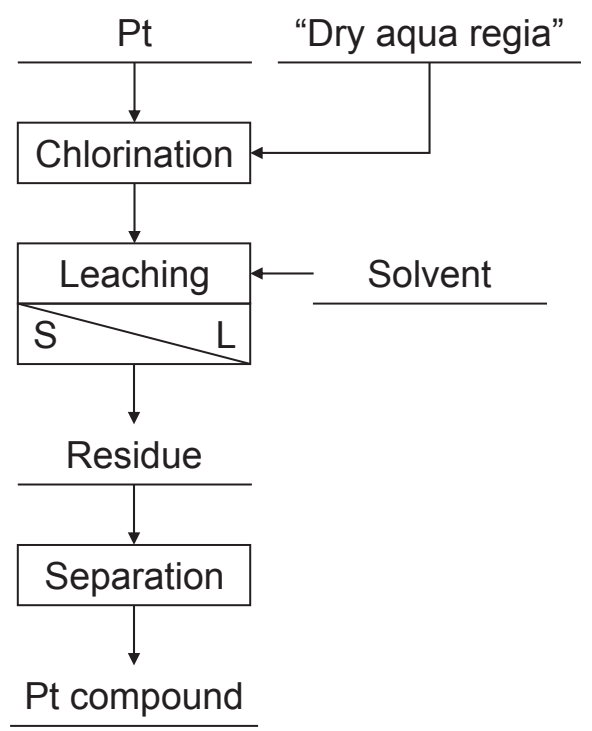

Fig. 1 Total flows of this research to recover Pt. 
However, the final recovered product was a platinum compound, and contaminated with potassium chloride or iron oxide $\left(\mathrm{FeO}_{\mathrm{x}}\right)$ that was generated from iron chloride (III) and oxygen $\left(\mathrm{O}_{2}\right)$. Thus, there was possibility of improving the method of recovery using the difference in the solubility in solvents.

Based on the above analysis, this study examined a method of recovering pure platinum by solid-liquid separation process using the difference of solubility of potassium hexachloroplatinate and sodium hexachloroplatinate $\left(\mathrm{Na}_{2}\left[\mathrm{PtCl}_{6}\right]\right)$, and the precipitation step using ammonium chloride.

\section{Method}

\subsection{Consideration of experimental conditions}

In regard to precipitating and recovering dissolved platinum with aqua regia, a method that uses ammonium chloride is known. ${ }^{7}$ Platinum is dissolved as hexachloroplatinic acid $\left(\mathrm{H}_{2}\left[\mathrm{PtCl}_{6}\right]\right)$ by aqua regia treatment, and it is precipitated as ammonium hexachloroplatinate $\left(\left(\mathrm{NH}_{4}\right)_{2}\left[\mathrm{PtCl}_{6}\right]\right)$ by the addition of ammonium chloride to the solution. Pure platinum is recovered by the teat treatment of precipitated ammonium hexachloroplatinate.

As previously mentioned, potassium hexachloroplatinate is considered to be poorly soluble, ${ }^{8)}$ whereas sodium hexachloroplatinate is considered to be highly soluble. ${ }^{9)}$ Therefore, if potassium hexachloroplatinate can be converted to sodium hexachloroplatinate, pure platinum can be recovered by the addition of ammonium chloride to this solution.

Existing studies that have investigated the solubility of potassium hexachloroplatinate have shown its solubility in solutions besides water such as in an aqueous solutions of potassium chloride and sodium chloride $(\mathrm{NaCl}) .{ }^{10)}$ Although its solubility in pure water at $20^{\circ} \mathrm{C}$ is approximately $0.77 \mathrm{~g}$ / $100 \mathrm{~mL}$, the solubility decreases drastically in an aqueous potassium chloride solution, and when the concentration of potassium chloride exceeds $0.1 \mathrm{~g} / 100 \mathrm{~mL}$, it becomes nearly undissolvable, as shown in Fig. 2. Contrastingly, in an aqueous sodium chloride solution, the solubility of potassium hexachloroplatinate is reported to increase as the increase of the concentration of sodium chloride.

Ion exchange is mentioned as the mechanism by which the solubility of potassium hexachloroplatinate increases in an aqueous sodium chloride solution. ${ }^{10}$ The dissociation reactions for the water-dissolved sodium chloride and potassium hexachloroplatinate are expressed in eqs. (2) and

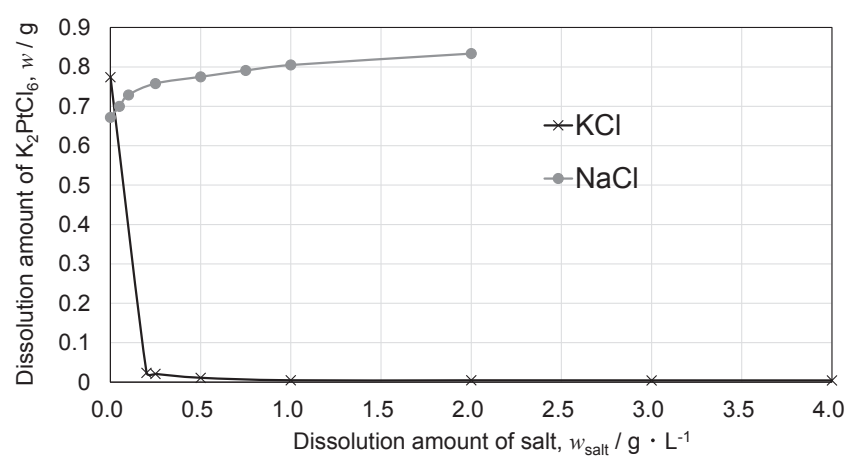

Fig. 2 Solubility of $\mathrm{K}_{2} \mathrm{PtCl}_{6}$ in $1.0 \mathrm{~L}$ of $\mathrm{KCl}$ and $\mathrm{NaCl}$ solutions.
(3), respectively. The transfer between the sodium ions and potassium ions during this stage is reported to make sodium hexachloroplatinate even more soluble.

$$
\begin{aligned}
\mathrm{NaCl} & \leftrightarrow \mathrm{Na}^{+}+\mathrm{Cl}^{-} \\
\mathrm{K}_{2}\left[\mathrm{PtCl}_{6}\right] & \leftrightarrow 2 \mathrm{~K}^{+}+\left[\mathrm{PtCl}_{6}\right]^{2-}
\end{aligned}
$$

Therefore, it is able to select the solubility of potassium hexachloroplatinate obtained by using iron chloride (III)potassium chloride-based dry aqua regia by choosing to use either an aqueous potassium chloride solution or aqueous sodium chloride solution when leaching.

Based on the above, in this study, a process was established, as shown in Fig. 3. By this process, a high purity platinum compound is recovered by removing the impurities. First, water or an aqueous potassium chloride solution is used during the first leaching attempt using dry aqua regia, where the potassium hexachloroplatinate precipitate-obtained via chloride processing-is preserved, whereas the unreacted iron chloride (III) and potassium chloride are removed. During the second leaching attempt using an aqueous sodium chloride solution, the potassium hexachloroplatinate is leached as sodium hexachloroplatinate, and the remaining solid iron oxide is separated and removed. Ammonium chloride is added to the solvent containing the above-mentioned sodium hexachloroplatinate, which is then precipitated as ammonium hexachloroplatinate and recovered. Finally, pure platinum is obtained by the heat treatment and of ammonium hexachloroplatinate.

Using the above process, it is possible to obtain pure platinum compound and avoid problems in the previous

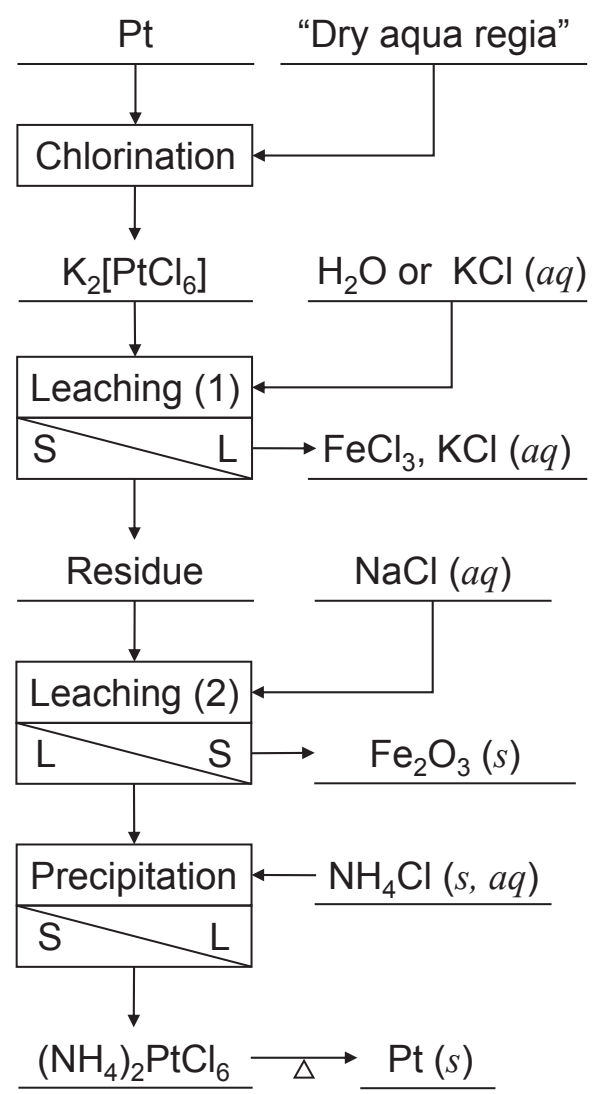

Fig. 3 Total flows of $\mathrm{Pt}$ recovery using $\mathrm{FeCl}_{3}-\mathrm{KCl}$ dry aqua regia and $\mathrm{NH}_{4} \mathrm{Cl}$. 
research where iron oxide is mixed as an impurity. ${ }^{5)}$ In this study, improvements in the recovery ratio as well as optimizing recycling methods were investigated via leaching and adjustments to the precipitation conditions.

\subsection{Experimental method}

The dissolution process of platinum using dry aqua regia was the same in the previous research. ${ }^{5)}$ A mixture of equimolar iron chloride (III) and potassium chloride was used as the dry aqua regia and adjusted to achieve a weight of $3 \mathrm{~g}$. Then, this adjusted mixture along with a platinum wire sample of approximately $100 \mathrm{mg}$ was deposited in a porcelain crucible $\left(\geq 58 \% \mathrm{SiO}_{2}, \geq 33 \% \mathrm{Al}_{2} \mathrm{O}_{3}\right.$ ). After the crucible was set in a glass reaction vessel and substituted with atmospheric argon (Ar), it was heated in a heating mantle until the reaction reached approximately $655 \mathrm{~K}$. After the thermocouple near the crucible showed a reading of $573 \mathrm{~K}$, the processing time was adjusted to $4 \mathrm{~h}$ to achieve dissolved platinum amount of approximately $35-40 \mathrm{mg}$.

After the completion of the reaction, the reaction vessel was removed from the heater and air cooled so that the dry aqua regia could solidify. The recovered dry aqua regia was leached by water or an aqueous potassium chloride solution and let to stand for $24 \mathrm{~h}$. Subsequently, the sediments recovered by filtering were leached with an aqueous sodium chloride solution and let to stand for $24 \mathrm{~h}$. Then, the precipitate was separated and removed by filtering, and ammonium chloride was added to the filtrate and let to stand for $24 \mathrm{~h}$. Then, the obtained precipitate was placed into a crucible, kept in a reaction vessel with argon gas flowing, and then heated at $655 \mathrm{~K}$ for $1 \mathrm{~h}$. The structure of the final obtained sample was identified via XRD (Rigaku, Ultima IV, $\mathrm{X}$-ray source: MoKa ray), and its composition was analyzed via SEM-EDS (JEOL, JSM-6010-LA). The platinum equivalent in the recovered product was estimated from its recovered weight and composition, and its recovery ratio was evaluated by comparing with the dissolved amount.

In this study, the following conditions were investigated: (1) the presence and absence of potassium chloride during the first leaching attempt, (2) the concentration and amount of the solution of sodium chloride during the second leaching attempt, and (3) the added amount of ammonium chloride during the precipitation process. The effects of the presence/ absence of potassium chloride during the first leaching
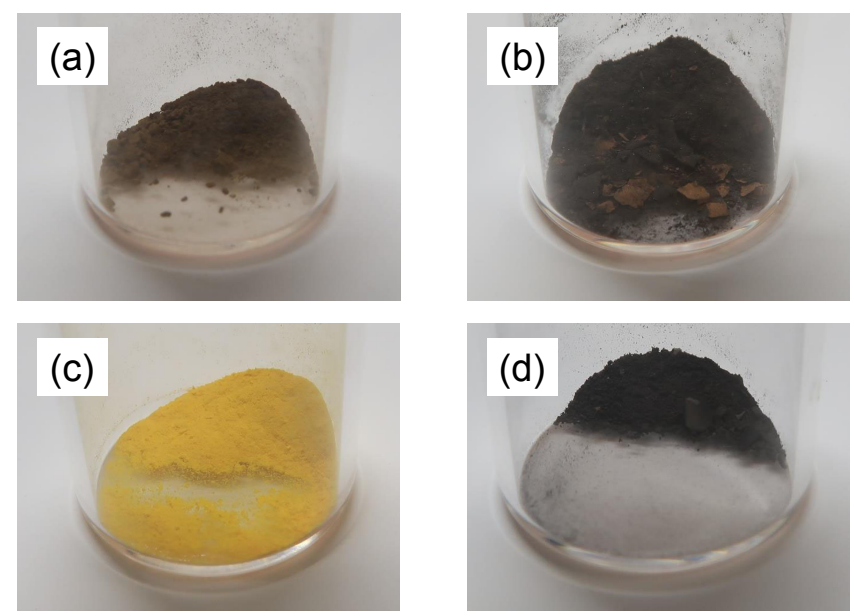

Fig. 4 Obtained powder, (a) by $\mathrm{KCl}$ solution leaching, (b) by $\mathrm{NaCl}$ solution leaching, (c) by $\mathrm{NH}_{4} \mathrm{Cl}$ addition, and (d) after thermal decomposition.

attempt (i.e., (1)) and the concentration and amount of the sodium chloride solution in the second leaching attempt (i.e., (2)) on the elution of potassium hexachloroplatinate were respectively evaluated. Additionally, the effects of the amount of ammonium chloride added during the precipitation process (i.e., (3)) on the precipitation of ammonium hexachloroplatinate were evaluated.

\section{Results and Discussion}

Figure 4 shows the precipitate obtained (a) by the leaching with the aqueous potassium chloride solution, (b) by the leaching with the aqueous sodium chloride solution, and (c) after adding ammonium chloride and (d) the recovered product obtained after the final heat treatment. Additionally, Fig. 5 shows the analyzed XRD results for the recovered products in (a) and (b). Both (a) and (b) exhibit a brown color, and are considered to be mostly iron oxide (III) based on the XRD analysis as well as the analyzed results in the previous research. ${ }^{5)}$ However, the peak for potassium hexachloroplatinate visible in (a) is not visible in (b). This is possibly owing to the elution of potassium hexachloroplatinate as sodium hexachloroplatinate on leaching with the aqueous sodium chloride solution. (a)

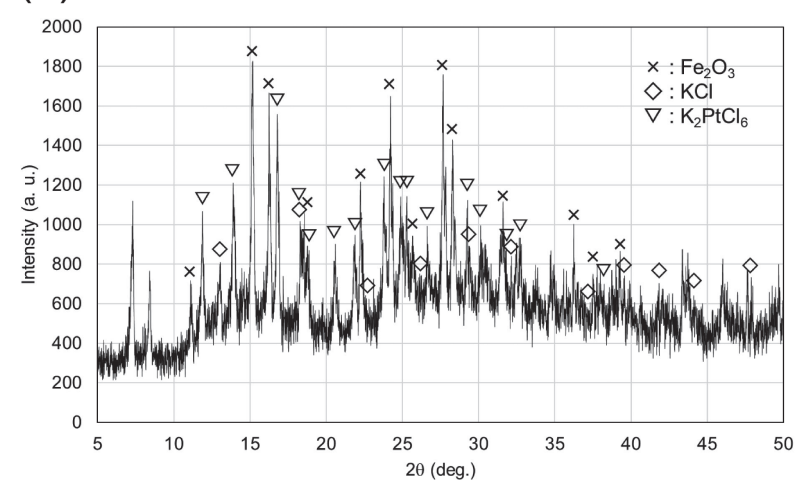

(b)

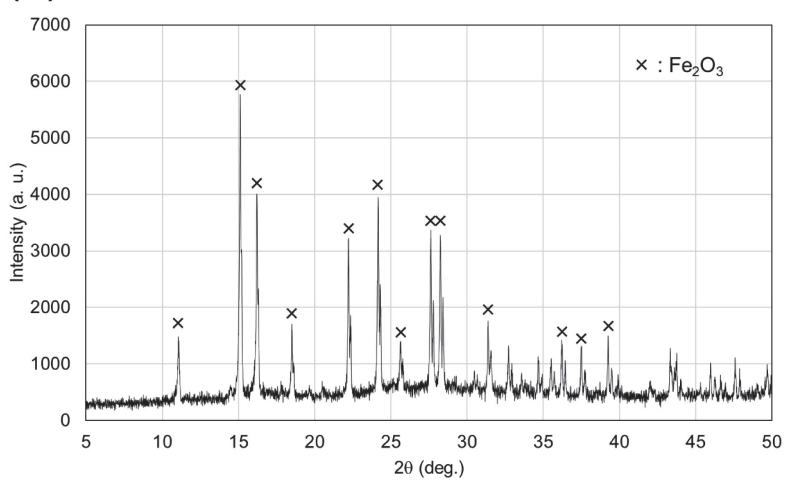

Fig. 5 Results of XRD analysis of the obtained powder, (a) by $\mathrm{KCl}$ solution leaching, and (b) by $\mathrm{NaCl}$ solution leaching. 
(a)

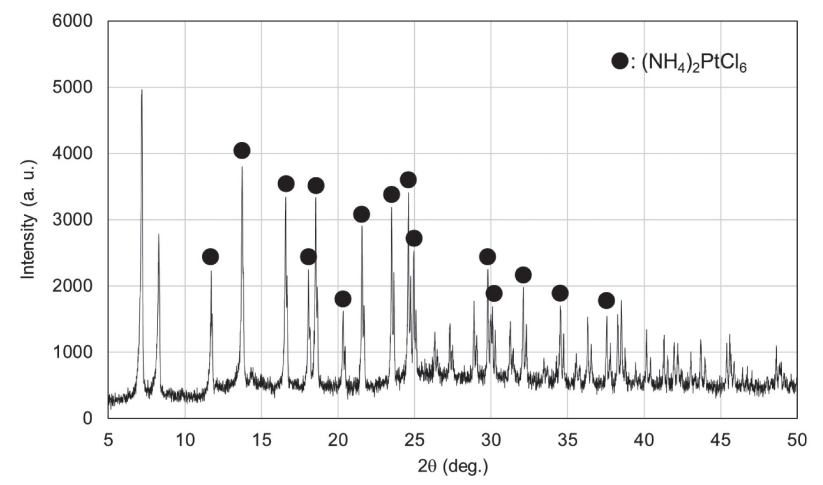

(b)

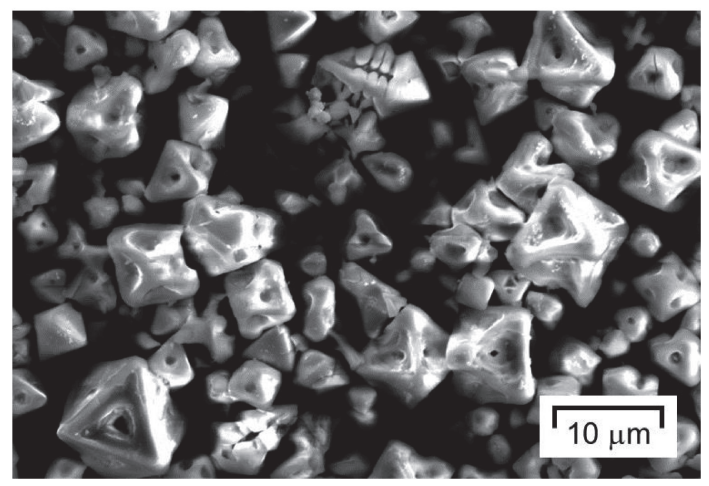

Fig. 6 Recovered material by $\mathrm{NH}_{4} \mathrm{Cl}$ addition, (a) XRD pattern, and (b) SEM image.

(a)

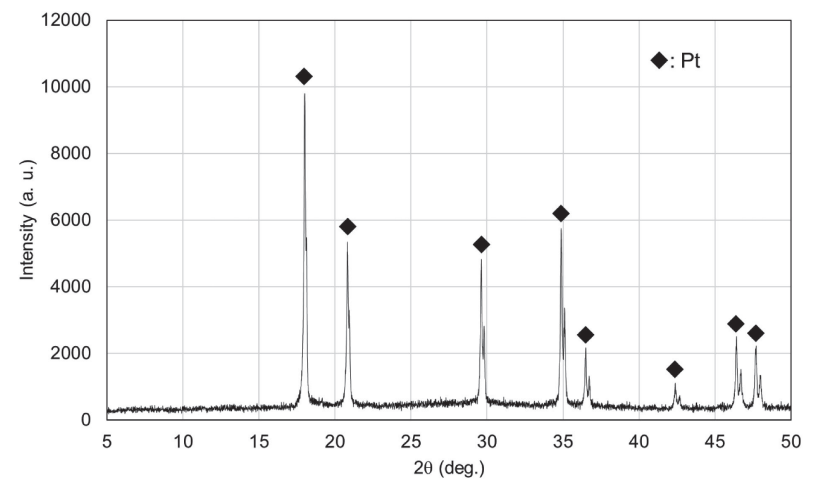

(b)

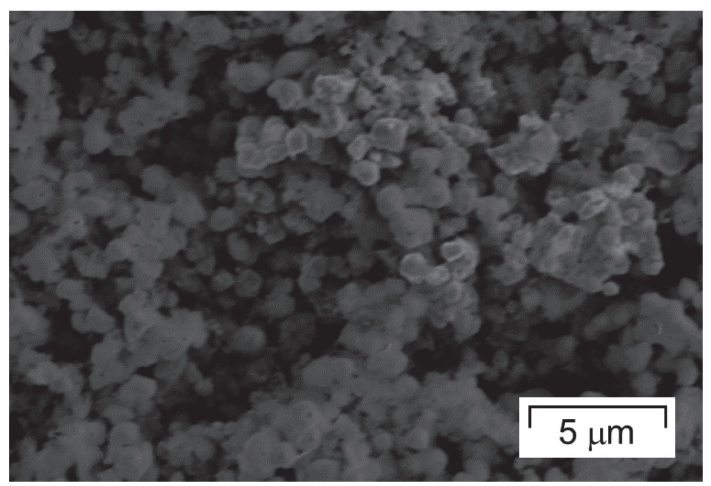

Fig. 7 Final recovered material, (a) XRD pattern, and (b) SEM image.

Figure 6 shows the results of the XRD analysis and observed results via SEM for the precipitate showing in Fig. 4(c), which was obtained after adding ammonium chloride. Based on the bright yellow color of the precipitate as well as the analyzed XRD results, it is confirmed to be near-pure ammonium hexachloroplatinate. The recovery from sodium hexachloroplatinate solution is confirmed, and this is similar to the typical recovery of platinum, ${ }^{7)}$ which obtain platinum compound by adding ammonium chloride to an aqueous hexachloroplatinic acid solution. Furthermore, it is possible that some of the precipitate may have been smaller than the diameter of the holes of the filter; this is based on the light yellow color of the solvent during filtration as well as on the tiny traces of crystallization observed via SEM. When this recovered product is resolved by heat treatment under atmospheric argon gas, the obtained final recovered product exhibits a black color Fig. 4(d).

The analyzed XRD results and SEM images for this final recovered product are shown in Fig. 7. Based on the only peak originating for the platinum detected by XRD as well as particles of $1 \mu \mathrm{m}$ confirmed in the SEM image, platinum seemed to be recovered as a form of platinum black or platinum sponge. ${ }^{11)}$ Therefore, it is probable that in this study, the reaction removes in particular the impurities derived from iron via a solid-liquid separation by following the process shown in Fig. 8. As previously mentioned, the authors recovered a platinum compound of low purity by mixing iron

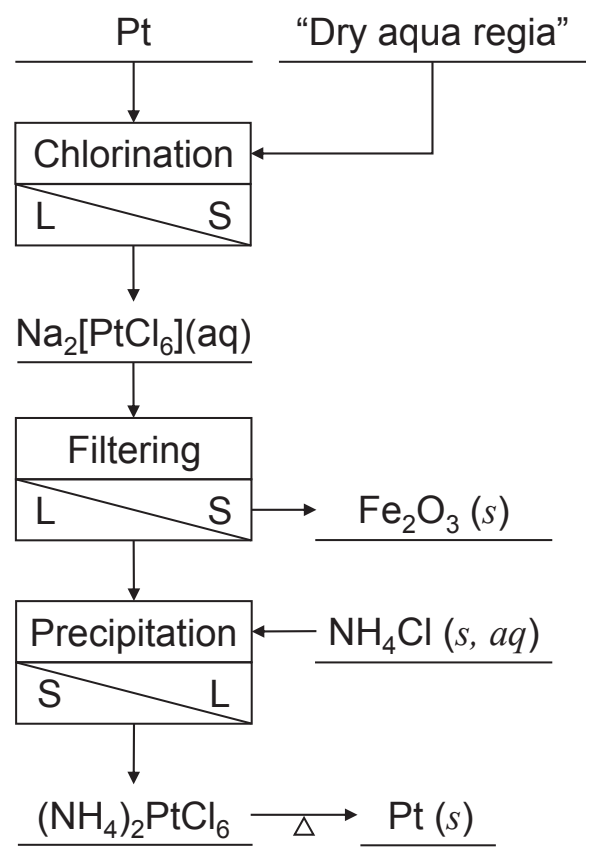

Fig. 8 Total flows of $\mathrm{Pt}$ recovery using $\mathrm{FeCl}_{3}-\mathrm{NaCl}$ dry aqua regia and $\mathrm{NH}_{4} \mathrm{Cl}$.

oxide in our previous studies, ${ }^{5)}$ and the recovery of pure platinum was confirmed via the method demonstrated in this study. Based on this, it is suggested that it is possible to 
Table 1 Recovery ratio obtained under the leaching and precipitation conditions.

\begin{tabular}{|c|c|c|c|c|c|c|c|}
\hline & $\begin{array}{l}\text { Pt dissolution, } \\
D_{\mathrm{Pt}_{\mathrm{t}}} / \mathrm{mg}\end{array}$ & $\begin{array}{l}\text { Leaching (1), } \\
w_{\mathrm{KCl}} / \mathrm{g}, l_{1} / \mathrm{mL}\end{array}$ & $\begin{array}{l}\text { Leaching (2), } \\
w_{\mathrm{NaCl} / \mathrm{g},} l_{1} / \mathrm{mL}\end{array}$ & $\begin{array}{c}\mathrm{NH}_{4} \mathrm{Cl} \text { addition, } \\
w_{\mathrm{NH} 4 \mathrm{Cl}} / \mathrm{g}\end{array}$ & $\begin{array}{c}\left(\mathrm{NH}_{4}\right)_{2} \mathrm{PtCl}_{6} \text { precipitation, } \\
w_{(\mathrm{NH} 4)_{2} \mathrm{PtCl} 6} / \mathrm{mg}\end{array}$ & $\begin{array}{c}\text { Pt recovery, } \\
w_{\mathrm{Pt}} / \mathrm{mg}\end{array}$ & $\begin{array}{c}\text { Recovery ratio } \\
R(\%)\end{array}$ \\
\hline$\# 1$ & 39.9 & 0,20 & $2.0,20$ & 8.0 & 36.0 & 15.1 & 37.8 \\
\hline$\# 2$ & 36.0 & 0,20 & $4.0,20$ & 4.0 & 33.5 & 11.4 & 31.7 \\
\hline$\# 3$ & 32.6 & 0,20 & $4.0,40$ & 8.0 & 33.6 & 11.9 & 36.2 \\
\hline$\# 4$ & 41.3 & $2.0,20$ & $2.0,20$ & 4.0 & 60.3 & 21.1 & 51.1 \\
\hline$\# 5$ & 36.3 & $2.0,20$ & $4.0,20$ & 4.0 & 34.2 & 15.5 & 42.3 \\
\hline \#6 & 37.7 & $2.0,20$ & $4.0,40$ & 8.0 & 64.7 & 29.7 & 78.8 \\
\hline
\end{tabular}

formulate a recycling process capable of recovering highpurity platinum using dry aqua regia.

Table 1 shows that the recovered platinum obtained under the leaching and precipitation conditions changes. The recovery ratio was reached approximately $80 \%$ in the case of \#6, which used the aqueous potassium chloride solution in the first leaching attempt, used the aqueous sodium chloride solution in the second leaching attempt, and added the enough amount of ammonium chloride at the time of precipitation. Contrastingly, for cases $\# 1$ to $\# 5$, in which the processes deviate from the optimal conditions from (1) to (3) in section 2.2 , the recovery ratios were limited between $30-50 \%$. Based on these results, it is suggested that the impurities need to be removed via a solid-liquid separation that uses leaching, and an optimal precipitation process needs to be set to effectively recover the dissolved platinum.

The elution of potassium hexachloroplatinate due to the use of pure water in (1) (\#1 to \#3) and the insufficient elution of sodium hexachloroplatinate due to the non-addition of a sufficient amount of sodium chloride solvent in (2) (\#1, \#2, $\# 4$, \#5) were thought to be the primary causes of the reduced recovery ratios under the other conditions. Additionally, under the conditions using a small addition of ammonium chloride in (3) (\#2, \#4, \#5), it is possible that the eluted sodium hexachloroplatinate is not sufficiently precipitated as ammonium hexachloroplatinate.

Additionally, based on the light yellow color exhibited by the solvent after the filtration, as previously mentioned, it is possible that some of the precipitate is not recovered when it is passed through the filter because it may have been smaller than the diameter of the holes of the filter. Because it is possible that this reduced the recovery ratio, the above scenario needs to be considered.

Potassium hexachloroplatinate was obtained by a process using dry aqua regia in this study, and if an iron chloride (III)sodium chloride-based dry aqua regia was to be used, then it is thought that sodium hexachloroplatinate could be obtained. As this compound is highly soluble in water, ${ }^{9}$ it is possible to reduce the number of leaching attempts. As shown in Fig. 8, ammonium hexachloroplatinate can be directly recovered by the addition of ammonium chloride to the solution obtained using the iron chloride (III)-sodium chloride-based dry aqua regia. However, because the iron chloride (III) that did not contribute to the reaction and the iron chloride (II) generated in the reaction in this process are included in the sodium hexachloroplatinate solution, ironbased compounds cannot be completed removed. Contrastingly, the process in this study has an advantage that can remove the iron-based compounds completely by the twice leaching attempt as shown in Fig. 3, and it is important to design a process that considers each feature.

\section{Conclusion}

In this study, a solid-liquid separation of platinum compositions using an aqueous potassium chloride solution and aqueous sodium chloride solution, as well as precipitation using ammonium chloride were possible. Furthermore, pure platinum was recovered by the heat treatment of the ammonium hexachloroplatinate. The maximum recovery was reached approximately $80 \%$ for the dissolution amount by performing the solid-liquid separation under optimal conditions, and the recovery was confirmed to be limited to $30-50 \%$ under non-optimal process conditions. This suggests a need to optimize the solid-liquid separation and precipitation step to improve the recovery ratio.

Although previous attempts in platinum recycling using dry aqua regia resulted in a potassium hexachloroplatinate precipitate with the issue of iron oxide mixed in the precipitate, it was possible to recover pure platinum using the new method established in this study.

In future studies, authors will use the iron chloride (III)sodium chloride-based dry aqua regia which can recover platinum by the small number of leaching attempts, and formulate an optimal process in conjunction with the system analyzed in this study.

\section{Acknowledgments}

This research was performed with the support of JSPS research grant $19 \mathrm{~K} 20483$. In conducting this research and donation from Hitachi Metals - Materials Science Foundation. We received much support from Professor T.H. Okabe and Associate Professor S. Yagi, from the Institute of Industrial Science, The University of Tokyo. In addition, Mr. Hidekazu Kato, a research associate at Chiba University, 
provided valuable research advice. We wish to express our gratitude.

\section{REFERENCES}

1) "Kobutsushigen Material Flow 2017, Hakkinzoku (PGM)". Japan Oil, Gas and Metals National Corporation: http://mric.jogmec.go.jp/wpcontent/uploads/2018/03/material_flow2017_PGM.pdf (Accessed 20187-30).

2) "GFMS PLATINUM \& PALLADIUM SURVEY 2017". THOMSON REUTERS. http://images.financial-risk-solutions.thomsonreuters.info/ Web/ThomsonReutersFinancialRisk/\%7B1680fcf5-2b58-4950-96511004a9b39aad\%7D_GFMS_Platinum_Group_Metals_Survey_2017.pdf (Accessed 2018-7-30).
3) T.H. Okabe, H. Nakata and K. Morita: Hyomen Kagaku 29 (2008) 592-600.

4) T. Yoshida: Kikinzoku Rare Metal no Recycle Gijutsu Shusei, (NTS Inc., Tokyo, 2007) pp. 76-148.

5) A. Yoshimura and Y. Matsuno: J. Jpn. Inst. Met. Mater. 83 (2019) 2329.

6) W.M. Barr: US. Patent 3,988,415, 1976-10-26.

7) Y. Arai: Kogyo Kyoiku Shiryo 337 (2011) 8-11.

8) MSDS of $\mathrm{K}_{2} \mathrm{PtC}_{6}$ : Showa Chemical Co. Ltd., http://www.st.rim.or.jp/ $\sim$ shw/MSDS/16230120.pdf (Accessed 2018-7-30).

9) F. A. Cotton: Inorganic Syntheses, Vol. 13, (McGraw-Hill, Inc., New York, USA) pp. 173-176.

10) E.H. Archibald, W.G. Wilcox and B.G. Burkley: J. Am. Chem. Soc. 30 (1908) 747-760.

11) A. Mills: Plat. Met. Rev. 51 (2007) 52. 